\title{
Evaluating natural ventilation provisions and occupants' ventilation behavior in five terrace housing types in Putrajaya, Malaysia
}

\begin{abstract}
This study investigates the natural ventilation provisions of residential buildings in the hothumid climate of Putrajaya as well as the occupants' utilization and overall satisfaction of these provisions. Five terrace house design types were selected for the study and natural ventilation $(\mathrm{NV})$ provisions were identified through acquired building documents. Computer simulations were carried out on all house types to determine the ventilation rates delivered by the NV provisions. Furthermore, a total of 298 households from the selected house types were surveyed. Two house types were found not to comply with the Uniform Building ByLaw (UBBL) governing NV provisions in Malaysia and those house types that complied were found to exhibit higher ventilation rates. Occupants' level of satisfaction when utilising $\mathrm{NV}$ was found to be significantly related to opening sizes complying with UBBL, longer duration of opening windows, and occupants' means of achieving comfort. This paper informs designers on the importance of complying with the required law governing $\mathrm{NV}$ in residential buildings. It also highlights the need for a strict effective enforcement of UBBL compliance for the purpose of building approvals.
\end{abstract}

Keyword: Hot-humid climate; Indoor air quality; Occupants' satisfaction; Residential buildings; Uniform Building By-Law; Ventilation rates 